\section{Spend more on soil clean-up in China}

Toxic chemicals from a contaminated site may be a factor in last month's serious sickness among 500 or so students in Changzhou in eastern China. To avoid adverse environmental effects on human health, the country must invest more in soil remediation and create tailored guidelines for decontamination.

Hundreds of thousands of factories have been demolished in China to make way for homes, schools and shopping centres. A national soil survey in 2014 revealed that more than $30 \%$ of old industrial land was still polluted (see go.nature.com/ a6s5y3; in Chinese). Despite this, the country's total budget for urban soil remediation in 2015 was paltry - roughly equivalent to US $\$ 300$ million, or just $0.003 \%$ of total gross domestic product.

China's current remediation guidelines for urban soil are based on those of the United States (see go.nature.com/lajaaw; in Chinese). However, the US guidelines were developed mainly for contaminated sites that had been built on, so the same standards may not apply to Chinese brownfield redevelopments. For example, China is more likely to overspend on remediating sites that could have high commercial value.

Such selective remediation, combined with the small budget, could limit the decontamination of urban soils and make it unsustainable.

Yijun Yao Zhejiang University, Hangzhou, China. yijun_yao@zju.edu.cn

\section{Use open data to curb Zika virus}

To avoid losing valuable knowledge and to accelerate decision-making during the current Zika public-health emergency, the World Health Organization (WHO) and international partners are renewing efforts to promote rapid sharing of the latest research data (see go.nature.com/qtf5 $\times 4$ ). Data sharing is important for all medical research, and particularly during outbreaks of such new and unstudied diseases (see, for example, N. L. Yozwiak et al. Nature 518, 477-479; 2015).

The International Committee of Medical Journal Editors has ruled that, in a WHO publichealth emergency, dissemination of raw information critical to public health will not prejudice later publication by researchers in the same journal. This is important, because it prioritizes open access and real-time disclosure over competition between researchers and companies rushing to publish successful trial results.

The Bulletin of the World Health Organization has also made publication of papers and raw data on Zika virus open-access and immediate (see go.nature. com/djfyzf). So far, more than 30 funding and research agencies and medical journals are supporting the initiative.

Failure to disclose medical research data promptly and publicly can give rise to misinformation, leading to treatments that are dangerous or ineffective, or to delays in effective treatments. It also wastes precious public-health resources. Marie-Paule Kieny, Vasee Moorthy, Daniela Bagozzi WHO, Geneva, Switzerland. bagozzid@who.int

\section{Restoration: avoid arbitrary baselines}

Janne Kotiaho and colleagues propose using a pre-degradation 'natural state' as a reference baseline for assessing the impact of humans on biodiversity and ecosystem function (Nature 532, 37; 2016). However, it is not possible for scientists to define a single such baseline objectively.

This is because global ecosystems changed drastically during pre-human time periods, under otherwise 'natural' conditions.

As long as scientists set

baselines to single time points in Earth's history, this problem will remain. The established solution is to compare the full ranges of variability in biodiversity and ecosystem functioning within and between pre-human and post-human worlds (see K. J. Willis and H. J. Birks Science 314, 1261-1265; 2006).

This approach avoids the need to set any arbitrary baselines for a 'natural state'. It also allows scientists to determine what effects human activities (such as nitrogen pollution or greenhouse-gas emissions) have on the planet, after expected ranges of natural changes have already been accounted for (see K. K. McLauchlan et al. Nature 495, 352-355; 2013).

Zia Mehrabi University of British Columbia, Canada.

zia.mehrabi@ubc.ca

\section{Restoration: 'Garden of Eden' unrealistic}

We consider the proposed use of a 'pre-degradation' state as a reference baseline for damaged ecosystems to be unrealistic (J. Kotiaho et al. Nature 532, 37; 2016). Instead of this 'Garden of Eden' baseline, we argue that restoration should respond to current drivers of biodiversity loss and decline in ecosystem function and services.

A baseline that prescribes a list of pre-degradation species is a good place to start, but it does not take into account the dynamism of ecological communities, in which species are constantly migrating, evolving and going extinct. Moreover, native species can be difficult to propagate and invasive species may be so prevalent that they are impossibly costly to remove. Present-day climate change may necessitate the use of non-local genotypes and even non-local native species to improve restoration outcomes (see M. F. Breed et al. Conserv. Genet. 14, 1-10; 2013 and R. J. Hobbs Rest. Ecol. 24, 153-158; 2016).

We suggest that restoration efforts should focus on a trajectory towards functional, self-sustaining ecosystems that are resilient to climate change and provide measurable ecosystem-service outcomes - as emphasized by the Intergovernmental SciencePolicy Platform on Biodiversity and Ecosystem Services (IPBES). Martin F. Breed, Andrew J. Lowe University of Adelaide, Australia. Peter E. Mortimer Kunming Institute of Botany; and World Agroforestry Centre, Kunming, China.

martin.breed@adelaide.edu.au

\section{Shark-fin landing policy aids control}

David Sims and Nuno Queiroz call for tighter fisheries regulations for species caught by European fleets as by-catch, using shortfin mako and blue sharks as examples (Nature 531, 448; 2016). However, their arguments with respect to these species have been overtaken by policy developments.

In 2013, the European Parliament and the Council of the European Union adopted a new regulation that amends a 2003 legal act about the removal of fins of sharks on board vessels. Sharks must now be landed with their fins attached, so gutted carcasses of swordfish can no longer be passed off as shortfin mako.

As an indicator of that policy's success, actual shortfin mako landings of the EU fleet made up $16.5 \%$ and $9.7 \%$ of blueshark landings in 2013 and 2014, respectively (go.nature. com/6fptm8), in line with the typical proportions quoted by Sims and Queiroz.

Alexander J. Stein European Commission, DirectorateGeneral for Maritime Affairs and Fisheries, Brussels, Belgium. alexander.stein@ec.europa.eu Disclaimer declared (see go.nature.com/yriggt for details). 